\title{
Examination of Kernel Based Noise Classifier with Cross Resolution Dataset and with Untrained Class
}

\author{
Ishuita SenGupta, Anil Kumar, Rakesh Kumar Dwivedi
}

\begin{abstract}
Determining the effect of untrained classes in the kernel based noise classifier is the prime object of the paper. It further includes, studying the effect of studied classifier over different datasets. Distinct nine Kernel functions has been associated with conventional supervised Noise Classifier. Landsat8 and Formosat2 along with Resourcesat-1 data have been opted for the performance evaluation. Decrease in classification accuracy has been found, in presence of untrained classes. A subtle consistency has been in classification accuracy in case of cross resolution data sets, thus, showing the robustness of the algorithm.
\end{abstract}

Keywords: Kernel functions, Noise Clustering Classifier, Cross Resolution, and Untrained Classes.

\section{INTRODUCTION}

Substantial applications of Remote Sensing have directed to availability of enormous magnitude of imagery. Prolonging the quality of imagery also has multiplied, ensuing to requirement of vigorous framework for image processing and evaluation.

The extensive use of fuzzy logic [26] for classification leads into soft classifiers. Among the most prominent fuzzy classifiers, Fuzzy c-mean algorithm had shown successful results over estimation and assessment of sub-pixel based data, although it failed to handle noise [9, 20]. Various classification techniques were implemented and Noise Clustering found to be unsurpassed [6, 7].

Studies related to spatial contextual information in the classification process illustrates improvement in the classifiers robustness against noise when compared to spectral based algorithm[13].Isolated pixels irregularity can be handled classifying using contextual classifiers. MRF based contextual has proven to be reliable classification with

Manuscript published on January 30, 2020.

* Correspondence Author

Ishuita SenGupta*, College of Computing Sciences and Information Technology, Teerthanker Mahaveer University, Moradabad, India. Email: ishuitasengupta8@gmail.com

Anil Kumar, Indian Institute of Remote Sensing, ISRO, Dehradun, India.Email: anil@iirs.gov.in

Rakesh Kumar Dwivedi, College of Computing Sciences and Information Technology, Teerthanker Mahaveer University, Moradabad, India.. Email: principal.computers@tmu.ac.in

(C) The Authors. Published by Blue Eyes Intelligence Engineering and Sciences Publication (BEIESP). This is an open access article under the CC-BY-NC-ND license

(http://creativecommons.org/licenses/by-nc-nd/4.0/) improved accuracy [3, 24]. Contextual support to Noise classifier was proposed earlier to overcome sensitivity of noise and outliers on the classification result using S-MRF or DA-MRF models [10].

Previous studies show that hybridization of conventional fuzzy based related to kernels have been done using different techniques. The underlying concept is mapping the data to higher dimension to make it linearly separable $[4,11]$. Different studies have been made with kernels to improve the classification. Associating Gaussian and higher order polynomial with unsupervised Noise Clustering algorithm found to be relatively more resistant against noise [5]. Similar study for noise robustness was examined by replacing Euclidean norm with Gaussian Kernel in PCM [12, 18]. Local kernel as well as the global kernels were studied and incorporated to enhance the capability of FCM [2]. In the similar form, study of incorporating eight kernels with Fuzzy c-Means has shown improved accuracy [4].

In supervised classification, it is impossible to get sample for all classes present in the study area or some of the classes may not be considered for classification. As a result, some of the classes are left untrained during classification. Lately, the effect of untrained classes during classification was also analyzed, with kernel based FCM, stating the presence of untrained classes affects the membership value and decreases the correspondence between the estimated and the actual class composition [4]. Similarly, kernels with PCM have shown high resistivity to untrained classes [14]. In supervised classification, the untrained class generated by escaping the training of classifier for a particular class. The similar examination has been opted for KNC classification.

This paper is the extension of the previous work done related kernel based noise classifier, KNC, using nine-kernel function in supervised model [16, 17]. The objective of present paper is to assess the associativity of untrained class upon kernel based noise classifier. Secondly, the paper also covers the effect of classification upon distinct resolution dataset.

\section{STUDY AREA AND DATASET DESCRIPTION}

The area of study is Haridwar district in state of Uttarakhand, India. Area extends from $29^{\circ} 52^{\prime} 49^{\prime \prime} \mathrm{N}$ to $29^{\circ} 54^{\prime} 2^{\prime \prime} \mathrm{N}$ and $78^{\circ} 9^{\prime} 43^{\prime \prime}$ E to $8678^{\circ} 11^{\prime} 25^{\prime \prime}$ E. The dataset used in classification are Landsat8 and Formosat2, with defined sensor details in Table 1 and Table 2. 
Table 1: Data Details of Landsat8[20]

\begin{tabular}{|c|c|c|}
\hline Spectral Band & Wavelength $(\boldsymbol{\mu m})$ & Resolution (m) \\
\hline $\begin{array}{c}\text { Band 1 - Coastal } \\
\text { aerosol }\end{array}$ & $0.43-0.45$ & 30 \\
\hline Band 2 - Blue & $0.45-0.51$ & 30 \\
\hline Band 3 - Green & $0.53-0.59$ & 30 \\
\hline Band 4 - Red & $0.64-0.67$ & 30 \\
\hline $\begin{array}{c}\text { Band 5 - Near Infrared } \\
\text { (NIR) }\end{array}$ & $0.85-0.88$ & 30 \\
\hline $\begin{array}{c}\text { Band 6 - Short } \\
\text { Wavelength Infrared 1 }\end{array}$ & $1.57-1.65$ & 30 \\
\hline $\begin{array}{c}\text { Band 7 -Short } \\
\text { Wavelength Infrared 2 }\end{array}$ & $2.11-2.29$ & 30 \\
\hline $\begin{array}{c}\text { Band 8 - } \\
\text { Panchromatic }\end{array}$ & $0.50-0.68$ & 30 \\
\hline Band 9 - Cirrus & $1.36-1.38$ & 15 \\
\hline
\end{tabular}

Table 2: Data Details of Formosat2[21]

\begin{tabular}{|c|c|c|}
\hline Spectral Band & Wavelength $(\boldsymbol{\mu m})$ & Resolution $(\mathbf{m})$ \\
\hline Band 1 - Blue & $0.45-0.52$ & 8 \\
\hline Band 2 - Green & $0.52-0.60$ & 8 \\
\hline Band 3 - Red & $0.63-0.69$ & 8 \\
\hline $\begin{array}{c}\text { Band 4 - Near } \\
\text { Infrared (NIR) }\end{array}$ & $0.76-0.90$ & 8 \\
\hline $\begin{array}{c}\text { Band 5 - } \\
\text { Panchromatic }\end{array}$ & $0.45-0.90$ & 2 \\
\hline
\end{tabular}

\section{EMPLOYED KERNEL METHODS}

Kernel methods direct to map the data to higher dimension to make it linearly separable $[1,19]$. The generalized mathematical expression shown in Eq.(3.2), where $(\varphi)$ denotes the mapping function that non-linearly maps the data to a higher dimensional feature space and the kernel function $(K)$ feature map given in Eq.(3.1).

$\Phi: R^{p} \rightarrow R^{q}$, where $\mathrm{p}<\mathrm{q}$

$K\left(\vec{x}, \overrightarrow{x_{i}}\right)=\phi(x) \cdot \phi\left(x_{i}\right)$

Table 3 displays the kernel methods used with algorithm. These nine kernels have been categorized as: four local kernels, three global kernels, spectral kernel, and hypertangent kernel [14].
Table 3: List of Kernel Methods Employed[16,17].

\begin{tabular}{|l|c|}
\hline \multicolumn{2}{|c|}{ Local Kernels } \\
\hline \multicolumn{1}{|c|}{ Kernel Name } & Mathematical Formulae \\
\hline $\begin{array}{l}\text { Radial Basis } \\
\text { Function }(R B F)\end{array}$ & $K\left(\overrightarrow{x_{i}}, \overrightarrow{v_{j}}\right)=e^{\left(\frac{\left\|x_{i}^{a}-v_{j}\right\|^{2}}{2 \sigma^{2}}\right)}$, where $\sigma, \mathrm{a}, \mathrm{b}>0$ \\
\hline
\end{tabular}

RBF kernel, defined by exponential function [4, 13]. $\sigma$ determines the width of the kernel; $a$ and $b$ are the constants. KMOD- (Kernel with Moderate Decreasing)

$$
K\left(\overrightarrow{x_{i}, v_{j}}\right)=e^{\left(\frac{\gamma}{\sigma^{2}+\left\|x_{i}-v_{j}\right\|^{2}}\right)^{-1}} \text {, where } \sigma, \gamma>0
$$

KMOD a distance based kernel function and shows better result in classifying closely related datasets[1].

\begin{tabular}{|c|c|c|c|}
\hline Gaussian & $K\left(\overrightarrow{x_{i}}, \overrightarrow{v_{j}}\right)=e$ & $-\frac{\left\|x_{i}^{a}-v_{j}^{b}\right\|^{2}}{2 \sigma^{2}}$ & , where $\sigma>0$ \\
\hline
\end{tabular}

The Gaussian kernel is a special case of radial basis function kernel[16].

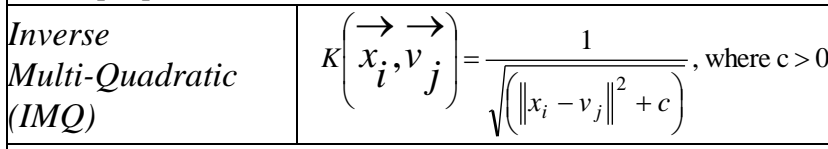

Here the value of $c$ was taken to be one.

\begin{tabular}{|l|l|}
\hline \multicolumn{2}{|c|}{ Global Kernels } \\
\hline Linear kernel & $K\left(\overrightarrow{x_{i}}, \overrightarrow{v_{j}}\right)=x_{i} \cdot v_{j}$ \\
\hline
\end{tabular}

It is the simplest and is defined as the inner product of the input feature vectors.

\begin{tabular}{|l|l}
\hline Polynomial & $\begin{array}{l}K\left(\overrightarrow{x_{i}}, \overrightarrow{v_{j}}\right)=\left(x_{i} \cdot v_{j}+c\right)^{P}, \text { where } \mathrm{c} \geq 0 \\
(\mathrm{P}=1 \text { to } 4)\end{array}$ \\
\hline
\end{tabular}

The polynomial kernel is a positive, where, $\mathrm{P}$ denotes the degree of the polynomial function and $\mathrm{c}$ is the constant.

Sigmoid

$$
K\left(\overrightarrow{x_{i}}, \overrightarrow{v_{j}}\right)=\tanh \left(\alpha \cdot x_{i} \cdot v_{j}+c\right)
$$

Sigmoid kernel is a hyperbolic tangent function.

The parameter $\alpha$ defines width of the kernel[15].

\begin{tabular}{|c|c|}
\hline$\alpha\left(x, v_{i}\right)=\arccos \left(\frac{\left(x . v_{i}\right)}{\|x\| v_{i} \|}\right)$ & $\begin{array}{l}\text { The spectral kernel works upon } \\
\text { the concept of spectral signature } \\
\text { concept and uses spectral angle } \\
\text { to determine vector distance[15] } \\
\text { - }\end{array}$ \\
\hline$K\left(x, v_{i}\right)=1-\tanh \left(-\frac{\left\|x-v_{i}\right\|^{2}}{\sigma^{2}}\right)$ & $\begin{array}{l}\text { The hyper tangent kernel is a } \\
\text { hyperbolic tangent function. The } \\
\text { adjustable parameter } \sigma \text { defines } \\
\text { the width of the kernel. It had } \\
\text { seen that this kernel outperforms } \\
\text { other kernels when applied to a } \\
\text { large data set [18]. }\end{array}$ \\
\hline
\end{tabular}

\section{CLASSIFICATION}

Supervised Kernel Based Noise Clustering (KNC)

This classifier was derived by using kernel methods with Noise classifier (NC) $[6,7,8]$. The objective function derived implies the replacement of Euclidean distance with the prescribed kernel function $K\left(x_{i}, v_{j}\right)$ 
$J_{K N C}(U, V)=\sum_{i=1}^{N} \sum_{j=1}^{C} \mu_{i j}^{m} K\left(x_{i}, v_{j}\right)+\sum_{i=1}^{N} \mu_{i, c+1}^{m} \delta$

To measure the non-linearity among the classes on the basis of spatial features, contextual support has been provided using MRF models with KNC. The study results in the generation of hybrid classifier and results were found promising $[18,19]$. Table 4 denotes the mathematical representation of hybrid classifiers.

\section{UNTRAINED CLASS AND CROSS RESOLUTION DATA SET DESCRIPTION}

\section{Untrained Class}

In supervised classification to get samples of all classes present in defined area of study is unattainable. Certain classes may not be considered for classification and thus represented as untrained. Such classes confirm showing high membership values for spectrally different class and thus, results in decrease of the classification accuracy [4].

\section{Cross-resolution Dataset}

To study the effect of classifier over different resolution data sets, AWiFS (Advanced Wide Field Sensor), LISS-III (Linear Imaging Self Scanner) and LISS-IV images from the Resourcesat-1 (Indian Remote sensing Satellite-P6) have been used in the studied classifier. The specifications are illustrated in Table 5.

Table 5: Data Details of Resourcesat-1[22]

\begin{tabular}{|l|c|c|c|}
\hline Specifications & LISS-IV & LISS-III & AWiFS \\
\hline $\begin{array}{l}\text { Spatial } \\
\text { resolution (m) }\end{array}$ & 5.8 & 23.5 & 56 \\
\hline & $\begin{array}{c}0.52-0.5 \\
9\end{array}$ & $0.52-0.59$ & $0.52-0.59$ \\
$\begin{array}{l}\text { Spectral Bands } \\
\text { (microns) }\end{array}$ & $\begin{array}{c}0.62-0.6 \\
8\end{array}$ & $\begin{array}{c}0.62-0.68 \\
0.77-0.86\end{array}$ & $\begin{array}{c}0.62-0.68 \\
0.77-0.86 \\
0.77-0.8\end{array}$ \\
$\begin{array}{l}6 \\
1.55-1.70\end{array}$ & $1.55-1.70$ \\
\hline $\begin{array}{l}\text { Quantization } \\
\text { (bits) }\end{array}$ & 7 & 7 & 10 \\
\hline
\end{tabular}

Table 4: Kernel based Contextual Noise Classifiers [14, 19]

\begin{tabular}{|c|c|}
\hline \multicolumn{2}{|r|}{ Kernel based Contextual Model } \\
\hline $\begin{array}{l}\text { Smoothness } \\
\text { Prior } \\
\text { KNC-S-MRF }\end{array}$ & $U\left(\frac{u_{i j}}{d}\right)=(1-\lambda)\left[\sum_{i=1}^{N} \sum_{j=1}^{C}\left(u_{i j}\right)^{m} K\left(\overrightarrow{x_{i}}, \vec{v}_{j}\right)+\sum_{i=1}^{N}\left(u_{i, C+1}\right)^{m} \delta\right]+\lambda\left[\sum_{i=1}^{N} \sum_{j=1}^{C} \sum_{j^{\prime} \in N_{j}} \beta\left(u_{i j}-u_{i j^{\prime}}\right)^{2}\right]$ \\
\hline $\begin{array}{l}\text { Discontinuity } \\
\text { Adaptive Prior } \\
\text { (Type 1) } \\
\text { KNC-DA1-MRF }\end{array}$ & $U\left(\frac{u_{i j}}{d}\right)=(1-\lambda)\left[\sum_{i=1}^{N} \sum_{j=1}^{C}\left(u_{i j}\right)^{m} K\left(\vec{x}_{i}, \vec{v}_{j}\right)+\sum_{i=1}^{N}\left(u_{i, C+1}\right)^{m} \delta\right]+\lambda\left[\sum_{i=1}^{N} \sum_{j=1}^{C} \sum_{j^{\prime} \in N_{j}}(-\gamma e)^{-\frac{\eta^{2}}{\gamma}}\right.$ \\
\hline $\begin{array}{l}\text { Discontinuity } \\
\text { Adaptive Prior } \\
\text { (Type 2) - } \\
\text { KNC-DA2-MRF }\end{array}$ & $U\left(\frac{u_{i j}}{d}\right)=(1-\lambda)\left[\sum_{i=1}^{N} \sum_{j=1}^{C}\left(u_{i j}\right)^{m} K\left(\overrightarrow{x_{i}}, \overrightarrow{v_{j}}\right)+\sum_{i=1}^{N}\left(u_{i, C+1}\right)^{m} \delta\right]+\lambda\left[\sum_{i=1}^{N} \sum_{j=1}^{C} \sum_{j^{\prime} \in N_{j}} \frac{-\gamma}{1+\frac{\eta^{2}}{\gamma}}\right.$ \\
\hline $\begin{array}{l}\text { Discontinuity } \\
\text { Adaptive Prior } \\
\text { (Type 3) - } \\
\text { KNC-DA3-MRF }\end{array}$ & $U\left(\frac{u_{i j}}{d}\right)=(1-\lambda)\left[\sum_{i=1}^{N} \sum_{j=1}^{C}\left(u_{i j}\right)^{m} K\left(\overrightarrow{x_{i}}, \overrightarrow{v_{j}}\right)+\sum_{i=1}^{N}\left(u_{i, C+1}\right)^{m} \delta\right]+\lambda\left[\sum_{i=1}^{N} \sum_{j=1}^{C} \sum_{j^{\prime} \in N_{j}}\left(\gamma \ln \left(1+\frac{\eta^{2}}{\gamma}\right)\right.\right.$ \\
\hline $\begin{array}{l}\text { Discontinuity } \\
\text { Adaptive Prior } \\
\text { (Type 4) - } \\
\text { KNC-DA4-MRF }\end{array}$ & $U\left(\frac{u_{i j}}{d}\right)=(1-\lambda)\left[\sum_{i=1}^{N} \sum_{j=1}^{C}\left(u_{i j}\right)^{m} K\left(\vec{x}_{i}, \vec{v}_{j}\right)+\sum_{i=1}^{N}\left(u_{i, C+1}\right)^{m} \delta\right]+\lambda\left[\sum_{i=1}^{N} \sum_{j=1}^{C} \sum_{j^{\prime} \in N_{j}}\left(\gamma|\eta|-\gamma^{2} \ln \left(1+\frac{\eta^{2}}{\gamma}\right)\right)\right]$ \\
\hline
\end{tabular}

\section{RESULTS}

Untrained class outputs have been computed by omitting to train the feature data of the particular class, here in this study water class was considered as untrained class. The process includes discarding a specific class while classifier training to quantify the robustness of kernel based noise classifier as well as its execution. The classifiers taken under consideration are KNC, KNC-SMRF, KNC-DA1MRF, KNC-DA2MRF, KNC-DA3MRF, and KNC-DA4MRF. Illustrations of Kernel wise overall accuracy is in Table 6, among them Hypertangent Kernel has shown more robustness in comparison to other kernels. On the other side, Polynomial kernels have shown zero effect upon classifier. Similarly, Table 7 displays the kernel wise overall accuracy when contextual support has been added using MRF models with KNC. Table 4 demonstrates the overall accuracy of Gaussian, Sigmoid and Hypertangent kernel. 
Table 6: Accuracy assessment results for trained and untrained class using KNC.

\begin{tabular}{|l|l|l|}
\hline Kernels & Untrained & Trained \\
\hline Linear & $8.23 \%$ & $11.35 \%$ \\
\hline Hypertangent & $81.62 \%$ & $82.19 \%$ \\
\hline Gaussian & $69.70 \%$ & $82.39 \%$ \\
\hline IMQ & $70.12 \%$ & $82.64 \%$ \\
\hline Radial & $69.75 \%$ & $81.60 \%$ \\
\hline $\begin{array}{l}\text { Polynomial( } \\
\text { Degree=1) }\end{array}$ & $7.23 \%$ & $11.16 \%$ \\
\hline
\end{tabular}

\begin{tabular}{|l|l|l|}
\hline $\begin{array}{l}\text { Polynomial( } \\
\text { Degree=2) }\end{array}$ & $0.00 \%$ & $0.00 \%$ \\
\hline $\begin{array}{l}\text { Polynomial( } \\
\text { Degree=3) }\end{array}$ & $0.00 \%$ & $0.00 \%$ \\
\hline $\begin{array}{l}\text { Polynomial( } \\
\text { Degree=4) }\end{array}$ & $0.00 \%$ & $0.00 \%$ \\
\hline KMOD & $69.12 \%$ & $82.15 \%$ \\
\hline Sigmoid & $66.14 \%$ & $79.25 \%$ \\
\hline Spectral & $85.33 \%$ & $90.66 \%$ \\
\hline
\end{tabular}

Table 7: Accuracy assessment results for trained and untrained class using KNC-SMRF, KNC-DA1MRF, KNC-DA2MRF, KNC-DA3MRF, and KNC-DA4MRF.

\begin{tabular}{|c|c|c|c|c|c|c|c|c|c|c|}
\hline $\begin{array}{c}\text { Contextual } \\
\text { Models }\end{array}$ & \multicolumn{4}{|c|}{ UNTRAINED } & \multicolumn{6}{|c|}{ TRAINED } \\
\hline (Classifier) & S-MRF & $\begin{array}{c}\text { DA1-M } \\
\text { RF }\end{array}$ & $\begin{array}{c}\text { DA2-M } \\
\text { RF }\end{array}$ & $\begin{array}{c}\text { DA3-M } \\
\text { RF }\end{array}$ & $\begin{array}{c}\text { DA4-M } \\
\text { RF }\end{array}$ & S-MRF & $\begin{array}{c}\text { DA1-M } \\
\text { RF }\end{array}$ & $\begin{array}{c}\text { DA2-M } \\
\text { RF }\end{array}$ & $\begin{array}{c}\text { DA3-M } \\
\text { RF }\end{array}$ & $\begin{array}{c}\text { DA4-M } \\
\text { RF }\end{array}$ \\
\hline $\begin{array}{l}\text { Gaussian } \\
\text { Kernel }\end{array}$ & $68.54 \%$ & $68.10 \%$ & $67.89 \%$ & $61.46 \%$ & $62.91 \%$ & $76.63 \%$ & $81.09 \%$ & $70.38 \%$ & $59.42 \%$ & $52.59 \%$ \\
\hline Sigmoid & $63.85 \%$ & $65.12 \%$ & $60.22 \%$ & $55.89 \%$ & $61.44 \%$ & $73.51 \%$ & $75.38 \%$ & $66.30 \%$ & $51.04 \%$ & $37.97 \%$ \\
\hline Hypertangent & $67.00 \%$ & $67.09 \%$ & $65.00 \%$ & $65.20 \%$ & $48.98 \%$ & $75.95 \%$ & $78.75 \%$ & $70.09 \%$ & $60.91 \%$ & $50.85 \%$ \\
\hline
\end{tabular}

Effect of studied classifiers on across resolution data sets

To analyze the impact, FERM (Fuzzy Error Matrix) based accuracy assessment results were computed [3,13]. The output images set off from finer resolution LISS-IV dataset as reference corresponding to AWIFS and LISS-III classification results. Table 8 and Table 9 show the overall accuracy across the different datasets using optimized range of fuzzifier $\mathrm{m}$ between 2.7 to 5.0 . The kernels taken into consideration KMOD and Spectral are best performing kernels in KNC. In similar pattern, for KNC with MRF Models Gaussian, Hypertangent and Sigmoid have been the outperformers [20]. The overall assessment shows minimal reflectance in performance with change in datasets, thus, retaining the robustness of the classifiers.

Table 8: Accuracy assessment results for KNC upon distinct datasets

\begin{tabular}{|c|c|c|c|c|c|c|c|c|}
\hline \multirow{2}{*}{$\begin{array}{l}m \\
\text { (Fuzzy } \\
\text { paramete } \\
\text { r) }\end{array}$} & \multicolumn{2}{|c|}{$\begin{array}{l}\text { AWIFS against LISS-IV } \\
\text { (Resourcesat-1) }\end{array}$} & \multicolumn{2}{|c|}{$\begin{array}{l}\text { AWIFS LISS-III } \\
\text { (Resourcesat-1) }\end{array}$} & \multicolumn{2}{|c|}{$\begin{array}{l}\text { LISS-III against LISS-IV } \\
\text { (Resourcesat-1) }\end{array}$} & \multicolumn{2}{|c|}{$\begin{array}{ll}\text { Landsat8 against } \\
\text { Formosat2 }\end{array}$} \\
\hline & KMOD & Spectral & KMOD & Spectral & KMOD & Spectral & KMOD & Spectral \\
\hline 2.7 & $86.85 \%$ & $88.02 \%$ & $91.41 \%$ & $92.85 \%$ & $87.37 \%$ & $90.39 \%$ & $80.02 \%$ & $88.79 \%$ \\
\hline 3 & $89.26 \%$ & $89.87 \%$ & $92.79 \%$ & $93.82 \%$ & $89.34 \%$ & $91.99 \%$ & $82.15 \%$ & $90.66 \%$ \\
\hline 3.5 & $90.26 \%$ & $92.20 \%$ & $93.93 \%$ & $95.42 \%$ & $91.14 \%$ & $93.62 \%$ & $85.14 \%$ & $92.77 \%$ \\
\hline 4 & $91.52 \%$ & $93.38 \%$ & $95.05 \%$ & $96.14 \%$ & $92.71 \%$ & $94.54 \%$ & $87.09 \%$ & $93.88 \%$ \\
\hline 4.5 & $92.96 \%$ & $94.25 \%$ & $95.56 \%$ & $96.53 \%$ & $93.69 \%$ & $95.45 \%$ & $88.54 \%$ & $94.65 \%$ \\
\hline 5 & $94.26 \%$ & $95.14 \%$ & $96.21 \%$ & $97.17 \%$ & $94.44 \%$ & $95.99 \%$ & $90.39 \%$ & $95.55 \%$ \\
\hline
\end{tabular}

Table 9: Accuracy assessment results for KNC-SMRF, KNC-DA1MRF, KNC-DA2MRF, KNC-DA3MRF, and KNC-DA4MRF upon distinct datasets

\begin{tabular}{|c|c|c|c|c|c|c|c|c|c|c|c|c|}
\hline \multirow[t]{2}{*}{\begin{tabular}{|l} 
Contextual \\
Classifier
\end{tabular}} & \multicolumn{3}{|c|}{$\begin{array}{l}\text { AWIFS against LISS-IV } \\
\text { (Resourcesat-1) }\end{array}$} & \multicolumn{3}{|c|}{ AWIFS LISS-III (Resourcesat-1) } & \multicolumn{3}{|c|}{$\begin{array}{l}\text { LISS-III against LISS-IV } \\
\text { (Resourcesat-1) }\end{array}$} & \multicolumn{3}{|c|}{ Landsat8 against Formosat2 } \\
\hline & $\begin{array}{l}\text { Gaussi } \\
\text { an }\end{array}$ & $\begin{array}{l}\text { Hypertag } \\
\text { ent }\end{array}$ & $\begin{array}{l}\text { Sigmoi } \\
\text { d }\end{array}$ & $\begin{array}{l}\text { Gaussia } \\
\text { n }\end{array}$ & $\begin{array}{l}\text { Hypertage } \\
\text { nt }\end{array}$ & $\begin{array}{l}\text { Sigmoi } \\
\text { d }\end{array}$ & $\begin{array}{l}\text { Gaussia } \\
\mathrm{n}\end{array}$ & $\begin{array}{l}\text { Hypertage } \\
\text { nt }\end{array}$ & $\begin{array}{l}\text { Sigmoi } \\
\text { d }\end{array}$ & $\begin{array}{l}\text { Gaussia } \\
\mathrm{n}\end{array}$ & $\begin{array}{l}\text { Hypertage } \\
\text { nt }\end{array}$ & $\begin{array}{l}\text { Sigmoi } \\
\mathrm{d}\end{array}$ \\
\hline \begin{tabular}{|l|} 
KNC-SA-MR \\
F
\end{tabular} & $84.63 \%$ & $84.07 \%$ & $80.10 \%$ & $89.88 \%$ & $94.29 \%$ & $87.26 \%$ & $88.21 \%$ & $85.31 \%$ & $84.09 \%$ & $76.63 \%$ & $75.95 \%$ & $73.51 \%$ \\
\hline $\begin{array}{l}\text { KNC-DA1-M } \\
\text { RF }\end{array}$ & $87.22 \%$ & $86.57 \%$ & $82.39 \%$ & $91.18 \%$ & $90.54 \%$ & $87.71 \%$ & $87.18 \%$ & $87.28 \%$ & $83.92 \%$ & $81.09 \%$ & $78.75 \%$ & $75.38 \%$ \\
\hline $\begin{array}{l}\text { KNC-DA2-M } \\
\text { RF }\end{array}$ & $80.53 \%$ & $81.10 \%$ & $72.82 \%$ & $77.37 \%$ & $88.03 \%$ & $87.12 \%$ & $84.38 \%$ & $82.81 \%$ & $78.61 \%$ & $70.38 \%$ & $70.09 \%$ & $66.30 \%$ \\
\hline
\end{tabular}




\begin{tabular}{|l|c|c|c|c|c|c|c|c|c|c|c|c|}
\hline $\begin{array}{l}\text { KNC-DA3-M } \\
\text { RF }\end{array}$ & $69.66 \%$ & $68.97 \%$ & $54.78 \%$ & $78.84 \%$ & $79.46 \%$ & $65.23 \%$ & $74.21 \%$ & $73.95 \%$ & $65.77 \%$ & $59.42 \%$ & $60.91 \%$ & $51.04 \%$ \\
\hline $\begin{array}{l}\text { KNC-DA4-M } \\
\text { RF }\end{array}$ & $53.71 \%$ & $55.61 \%$ & $46.35 \%$ & $64.14 \%$ & $69.09 \%$ & $58.28 \%$ & $68.04 \%$ & $66.90 \%$ & $57.21 \%$ & $52.59 \%$ & $50.85 \%$ & $37.97 \%$ \\
\hline
\end{tabular}

\section{CONCLUSION}

The paper focuses to assess the strength of classification algorithms KNC, KNC-SMRF, KNC-DA1MRF, KNC-DA2MRF, KNC-DA3MRF, and KNC-DA4MRF. Incorporation of untrained class and the effect of using different datasets has been the prime thrust of study. Results presented shows slight decrease in overall accuracy of the kernel-based classifiers, and Hypertangent Kernel has shown the minimal transform in accuracy. For cross resolution data AWIFS, LISS-III and LISS-IV images from the Resourcesat-1 (Indian Remote Sensing Satellite-P6) have been used in the studied classifier and have resulted in with minor change in overall accuracy. Thus, concluding that supplanting another dataset with studied classifiers have not influenced the robustness of kernel based noise classifier.

\section{REFERENCES}

1. Ayat, N. E., M. Cheriet, L.Remaki and C.Y. Suen (2001). KMOD-A New Support Vector Machine Kernel With Moderate Decreasing In Document Analysis and Recognition, (2001). Proceedings, Sixth International Conference, pp.1215-1219.

2. Bhatt, S. R. and P.K.Mishra (2013). Study of Local Kernel with Fuzzy C Mean Algorithm. International Journal of Advanced Research in Computer \& Software Engineering, 3(12), pp. 636-639.

3. Binaghi, E., P. A. Brivio, P. Chessi and A. Rampini (1999): A fuzzy set-based accuracy assessment of soft classification. Pattern Recognition Letters, 20(9), pp.935-948.

4. Byju, A. P. (2015). Non-Linear Separation of classes using a Kernel based Fuzzy c -Means (KFCM) Approach. MSc. Thesis, ITC, University of Twente,The Netherlands.

5. Chotiwattana, W. (2009). Noise Clustering Algorithm based on Kernel Method. Advance Computing Conference(2009). IACC 2009. IEEE, pp.56-60.

6. Dave, R. N. (1991). Characterization and detection of noise in clustering. Pattern Recognition Letters, 12,pp. 657-664.

7. Dave, R. N. (1993). Robust fuzzy clustering algorithms. Second IEEE International Conference on Fuzzy Systems 1993,pp. 1281-1286.

8. Dave, R. and S. Sen (1997). Noise clustering algorithm revisited. Fuzzy Information Processing Society, NAFIPS'97 (1997). Annual Meeting of the North American, IEEE, pp. 199-204.

9. Foody, G. M. (2000). Estimation of sub-pixel land cover composition in the presence of untrained classes. Computers \& Geosciences, 26(4), pp. 469-478.

10. Harikumar, A. (2014). The effects of discontinuity adaptive MRF models on the Noise classifier. MSc. Thesis, ITC, University of Twente, The Netherlands.

11. Hofmann, T, Scholkopf, B., and Smola, A. J. (2008). Kernel methods in machine learning. The Annals of Statistics, 36(3), 1171-1220.

12. Kandpal, N. (2016). Non-Linear Separation of classes using a Kernel based Possibilistic c -Means. MSc. Thesis, ITC, University of Twente, The Netherlands.

13. Kumar, A, Ghosh, S, Dadhwal, V. (2006). Sub-pixel land cover mapping: SMIC system. ISPRS Int. Sym."Geospatial Databases for Sustainable Development”, Goa, India, September 27-30, 2006.

14. Li, S. Z. (2009). Markov random field modeling in image analysis, Advances in Computer Vision and Pattern Recognition, Springer.

15. SenGupta, I., A. Kumar and R. K. Dwivedi (2018). Study of SigmoidSpectral Composite Kernel based noise classifier with entropy in handling non linear separation of classes. 5th IEEE Uttar Pradesh Section International Conference on Electrical, Electronics and Computer Engineering (UPCON), 2018.

16. SenGupta, I., A. Kumar and R. K. Dwivedi (2019). Performance Evaluation of Kernel-Based Supervised Noise Clustering Approach, Journal of Indian Society of Remote Sensing., 47(2), pp. 317-330.https://doi.org/10.1007/s12524-019-00938-2.

Retrieval Number: E6539018520/2020@BEIESP

DOI: 10.35940/ijrte.E6539.029420

Journal Website: www.ijrte.org
17. SenGupta, I., A. Kumar and R. K. Dwivedi (2019). Assimilation of Standard Regularizer Contextual Model and Composite Kernel with Fuzzy-based Noise Classifier, Journal of Modeling and Optimization 2019;11(1):16-24. https://doi.org/10.32732/jmo.2019.11.1.16

18. SenGupta, I., A. Kumar and R. K. Dwivedi (2019).Study of discontinuity adaptive MRF models with kernel-based noise classifier, Indian Journal of Geomatics,Indian Society of Geomatics 2019:13(1), 61-73.

19. Solberg, A. H., T. Taxt and A.K. Jain(1996). A Markov random field model for classification of multisource satellite imagery. Geoscience and Remote Sensing, IEEE Transactions, 34 (1), pp.100-113.

20. https://landsat.usgs.gov

21. https://directory.eoportal.org

22. https://data.gov.in

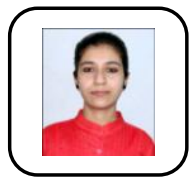

\section{AUTHORS PROFILE}

Ms. Ishuita SenGupta is a research scholar at Teerthanker Mahaveer University, Moradabad. She received BCA degree from M. J. P. Rohilkhand University in 2007 and MCA degree from Uttar Pradesh Technical University. She is the author of more than 15 research papers.She is also an active member of IEEE WIE. She is having the academic experience of more than 5 years. Her current research interests include Remote Sensing, Machine Learning, Data Mining and IoT (Internet of Things) and application development..Presently, she is working as academician in Meerut Institute of Technology, Meerut.

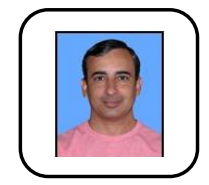

Dr. Anil Kumar is Scientist/Engineer 'SG' and presently working as head in Indian Institute of Remote Sensing (ISRO, Dept. of Space, Govt. of India), Dehradun, India as Head of Photogrammetry and Remote Sensing Department. He received his B.Tech and ME degrees in civil engineering from University of Lucknow and from IIT Roorkee in 1992 and 1997 , respectively, and his $\mathrm{PhD}$ degree in soft computing from the Indian Institute of Technology(IIT), Roorkee in 2007.

He is having more than 23 Years of experience in teaching as well as in research Soft Computing application for temporal images in specific class identification, Digital Photogrammetry, LiDAR, GPS. He is the recipient of many academic awards. He is the author of more than 40 journal papers and more than 50 conference papers. His current research interests include Deep Learning, Remote Sensing Temporal Data processing, LiDAR, GNSS, and Digital Photogrammetry.



Prof. (Dr.) Rakesh Kumar Dwivedi is presently working in Teerthanker Mahaveer University, Moradabad, India as Principal of College of Computing Sciences and Information Technology. He received his $\mathrm{PhD}$ degree in soft computing from the Indian Institute of Technology (IIT), Roorkee in 2014.

He is having more than 20 Years of experience in teaching as well as in research. He is the author of more than 30 journal papers. His current research interests include Soft Computing, Machine Learning, Deep Learning, and Software Project Development. 